\title{
Determinants of short stature in normal children at the age of two years: a case-control study in a community in Jerusalem
}

\author{
JACOBA GEEFHUYSEN \\ From the Institute of Social Medicine, Free University, Amsterdam
}

BELA ADLER AND HAVA PALTI

From the Department of Social Medicine, Hebrew University-Hadassah Medical School, Jerusalem

SUMMARY Differences were analysed between growth patterns and determinants of physical growth in two groups of normal infants at 24 months. Longitudinal data routinely collected in a mother and child clinic were analysed. At 24 months, $26 \%$ of cohort infants were at or below the 10th percentile for length (= 'small' infants); 98 of these were compared with 83 'medium' infants (between the 50th and the 75th percentile, for example). Excessive downward deviation of length percentiles was seen in $80 \%$ of 'small' infants. In $20 \%$ their birthweight was on the 10 th percentile or below; $50 \%$ had a mother less than $155 \mathrm{~cm}$ tall; maternal stature was closely linked with socioeconomic factors. Of mothers with less than nine years of schooling, 70\% had 'small' infants. In $95 \%$ of both groups growth attainment at two years could be predicted from data at 12 months. The known factors influencing deviant physical growth overlap with those of mental and social development. Growth deviation by itself may identify infants open to multiple risks, especially if their mothers have a low educational level. Further narrowing of the target group for specialised intervention strategies should be attempted.

The link between poor physical development at an early age and subsequent inadequate mental development has been difficult to prove. The overlap of common factors suggests that poor growth may be a useful indicator of infants at risk of less than optimal mental development. ${ }^{1-4}$ In this study we analyse some differences in growth patterns and circumstances between children who have and have not grown well by the age of two years.

All infants born in a selected neighbourhood of western Jerusalem attend a community programme for the promotion of growth and development $(P R O D)^{5}$ for children aged 0-5 years, run by the Department of Social Medicine. Routine monitoring of physical growth has revealed an excess of children below the 10th percentile for length at two years.

To elucidate differences between those children who do not appear to fulfil their growth potential and those who do, two groups of children were compared, namely, a group below the 10th percentile for length with a group of average growth. These groups were set against the background of the population as a whole with regard to demographic and social variables, the circumstances of pregnancy and delivery, and hospitalisation in the first year of life.

\section{Materials and methods}

A retrospective analysis was undertaken of the PROD records for the birth cohorts of 1973-74 and the study population was chosen from the 438 infants who attended for the second year examination:

Group I ( $n=98)$ 'Small' infants: length, or length and weight, at or below the 10 th percentile.

Group II $(n=83)$ 'Medium' infants: length, or length and weight, above the 50 th and at or below the 75th percentile.

Infants chosen for groups I and II had to be a singleton birth and to have no major abnormality or malformation $^{6}$; at least one previous measurement at 
one year or nine months of age had to be available. An additional group of normal singleton infants $(n=16)$ with a birthweight equal to or below the 10th percentile was analysed to establish the contribution of birthweight to the size at 24 months. These children did not otherwise fulfil the criteria of Groups I and II. Excluded were 12 twin individuals, two infants with congenital abnormalities, 199 who were not in the designated percentile groups, and 28 with inadequate records.

Routine measurements of growth included the weight at birth and weight and length at three, six, nine, 12 , and 24 months. ${ }^{7}$ Age limits were defined as follows: three and six months \pm 2 weeks, 12 months \pm 4 weeks, or, when not available, at nine months $-2+4$ weeks, 24 months \pm 10 weeks. In order to visualise clearly differences in growth, comparisons were made in centiles rather than in actual measurements. Concordance of measurements of the infant population in the study area with the US reference standard at different ages has been explored. ${ }^{78}$

The National Center for Health Statistics US Reference Standard ${ }^{9}$ was used to calculate age- and sex-specific percentiles for weight, length, and weight-for-length at actual ages, recalculated to intervals of five centiles at age differences of one week. This allowed direct grouping of infants at the designated age limits despite age differences of between four and 20 weeks. The data on progress of pregnancy, delivery, and the state of health of the baby at birth were extracted from the records of the '28th day' programme. ${ }^{5}$ Region of origin pertained to the. birthplace of the mother: 'Asia' without Israel, 'West' including Europe, America, South Africa, Australia, and Cyprus. For 'father's occupational status', the British Registrar General's occupational scale adapted for Israel was used ${ }^{5}$; occupational classes I and II were combined ('high') and classes IV, V, and unemployed ('low'). Cohort data for these items were derived from records of mothers giving birth in the first half of 1973 and the second half of 1974. As stated, these were compared with data available for mothers from the same area giving birth in 1974-76. Analysis was carried out by computer using the SPSS system $1970 .{ }^{10}$

\section{Results}

GROWTH PATTERNS

(i) Cohorts

Fig. 1 shows that there was an excess of $16 \%$ of children less than the 10 th percentile for length and just over $10 \%$ excess between the 10th and 25 th percentiles for both length and weight at the age of 24 months compared with the US standards in the cohort population of 1973-74.

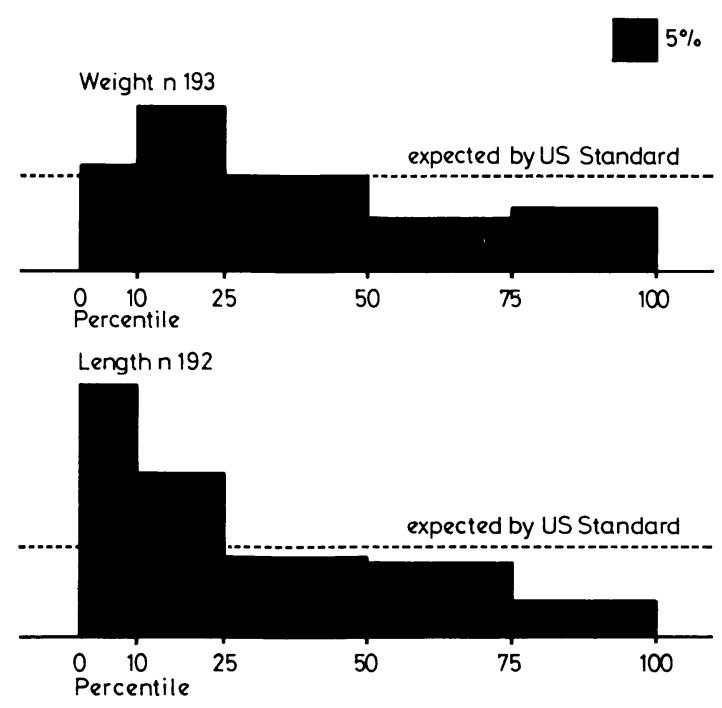

Fig. 1 Percentage distribution of weight and length percentiles at 24 months of age (distribution based on first half of 1973 and second half of 1974 cohorts).

\section{(ii) Groups}

The cumulative frequency distributions for lengt促 and weight percentiles at three, 12, and 24 month 8 (Figs. 2 and 3) show that at three months of age the distribution of the small infants was already in the lower percentile range (65\% for length and $45 \%$ fo weight). At 12 months there is a further shift of this group towards the lower percentiles $(95 \%$ for length), while in the 'medium' group a shift towards the upper percentiles is seen at both ages. These tendencies are more marked for length than for weight. At 12 months none of the 'small' group remain above the 50th percentile for length and only $10 \%$ for weight.

In the 'medium' group all are above the 50th percentile for length at 12 months; $36 \%$ remain between the 25 th and 50 th percentiles for weight, while $30 \%$ are above the 75 th percentile. These growth trends were also shown in individual infants by a comparison of relative length deviations of 10 centiles or more between serial measurements. Of the 'small' infants, $80 \%$ dropped 10 centiles or more below their starting percentile. Prediction of the 24-month percentile level was possible on the basis of their own growth trend available at 12 months in all but six of 25 infants in Group I and three of 15 infants in Group II, who had not yet entered the designated 24-months' group percentiles at age 12 months.

The percentage of infants below the 25th percentile for weight-for- length increased with age in the 'small' children, reaching $39 \%$ at 24 months. In 


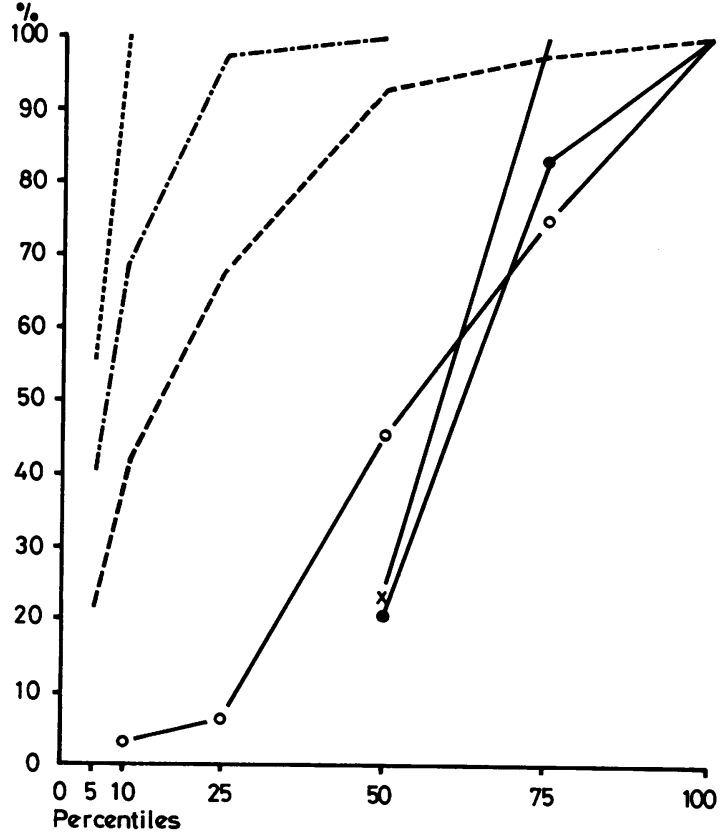

Group 1: -...-1-.-1--1 n 56-95

Group 2:0-o/x-x/0 $\rightarrow /$ n $66-83$

Fig. 2 Cumulative frequency diagram oflength percentiles at three, 12, and 24 months of age by sample groups.

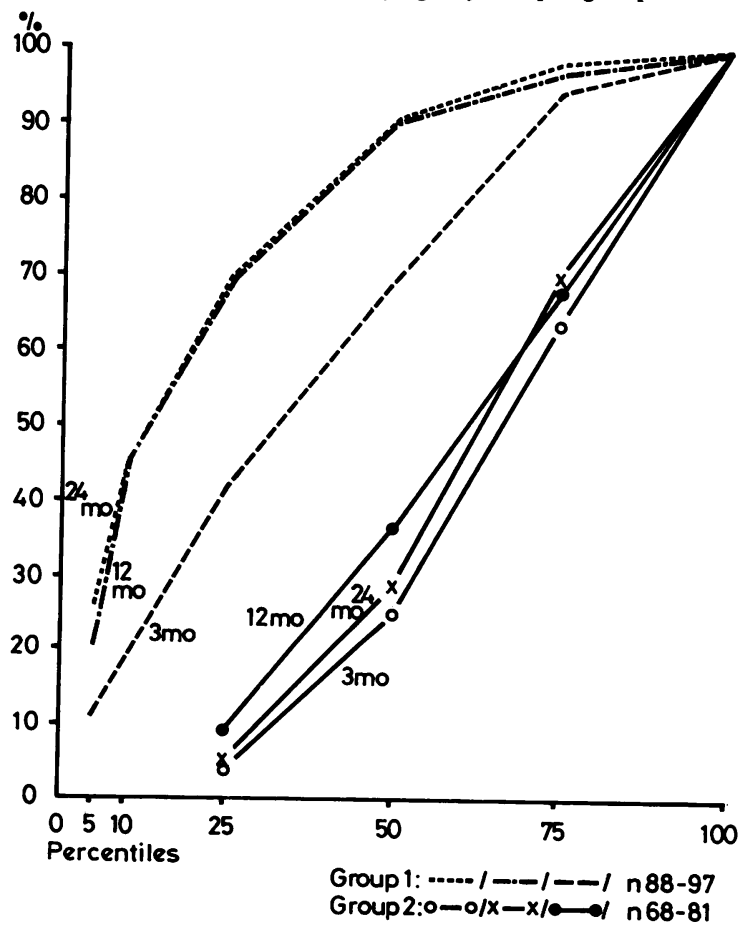

Fig. 3 Cumulative frequency diagram of weight percentiles at three, 12, and 24 months of age by sample groups. the 'medium' children at that age the proportion was only $9 \%$ (Table 1 ). The corresponding figures for the entire cohorts were as expected from the US standard, namely $25 \%$ below 25 th, $48 \%$ between 25 th and 75 th, and $27 \%$ above the 75 th percentile. At 12 months there was a sex difference in both sample groups below the 25 th percentile for weight-for-length-10\% more boys than girls. At 24 months this difference had disappeared in the 'medium' group but had increased to $20 \%$ in the 'small' group-boys 50\%, girls $30 \%$.

(iii) Birthweight below 10th percentile

Of the cohorts, $39(10 \%)$ of normal singleton infants had a birthweight below the 10th percentile; of these, 17 remained in Group I, and six entered Group II. The remaining 16 were analysed separately; at 24 months 15 had a length between the 10th and 50th percentiles and one infant was taller than the 75th percentile. The gestational ages of 27 of the 39 infants were known; nine had a gestation of 36 weeks or less, four in Group I, two in Group II, and three of the separately analysed infants. An additional three infants with a gestational age of 36 weeks had a birthweight above the 10 th percentile-one in Group $I$ and two in Group II. Of the remaining 18 infants with a gestational period of more than 36 weeks, seven were small for gestational age, that is, below the 5th percentile for birthweight ${ }^{1111}$ _-five in Group I and one in Group II.

MOTHER'S STATURE AND EDUCATIONAL LEVEL; RELATIONSHIP WITH FATHER'S OCCUPATION AND MOTHER'S REGION OF ORIGIN

Of the mothers of 'small' infants, $50 \%$ were below $155 \mathrm{~cm}$ in stature, while only $13 \%$ of the 'medium' infants had such short mothers. This is a highly significant difference (Table 2). There was also a significant difference between the educational levels of the mothers: $35 \%$ of the mothers of 'small' infants and $15 \%$ of the mothers of 'medium' infants had had eight years of schooling or less, while $13 \%$ and $38 \%$ respectively had had 13 years of schooling or more (Table 2).

The percentages of the general population of mothers giving birth were $22 \%$ with eight years of schooling or less and $30 \%$ with 13 years or more.

The difference in growth percentiles at 24 months by educational level of the mothers in the cohorts was greatest for length $(P<0.01)$ and least for weight-for-length (Fig. 4). In both sample groups the infants of mothers with nine to 12 years of schooling were the most proportionate (Table 3 ).

There was a strong relationship between the mother's stature and her educational level, both in the cohorts as a whole and in the sample groups 
Table 1 Weight-for-length distribution (in percentiles) at 3, 12, and 24 months of age by sample groups (percentages)

\begin{tabular}{|c|c|c|c|c|c|c|}
\hline \multirow[t]{3}{*}{ Age (months) } & \multicolumn{6}{|c|}{ GROUPS } \\
\hline & \multicolumn{6}{|c|}{ Percentiles } \\
\hline & $\leqslant 25$ & $>25 \leqslant 75$ & $>75$ & $\leqslant 25$ & $>25 \leqslant 75$ & $>75$ \\
\hline & \multicolumn{6}{|c|}{ Percentages } \\
\hline $\begin{array}{r}3 \\
12 \\
24\end{array}$ & $\begin{array}{l}(5) \\
26 \\
39\end{array}$ & $\begin{array}{l}56 \\
51 \\
45\end{array}$ & $\begin{array}{l}39 \\
23 \\
16\end{array}$ & $\begin{array}{c}(5) \\
16 \\
9\end{array}$ & $\begin{array}{l}69 \\
54 \\
69\end{array}$ & $\begin{array}{l}26 \\
30 \\
22\end{array}$ \\
\hline
\end{tabular}

Table 2 Distribution of mother's educational level and stature by sample groups and total population of mothers giving birth in 1974-76

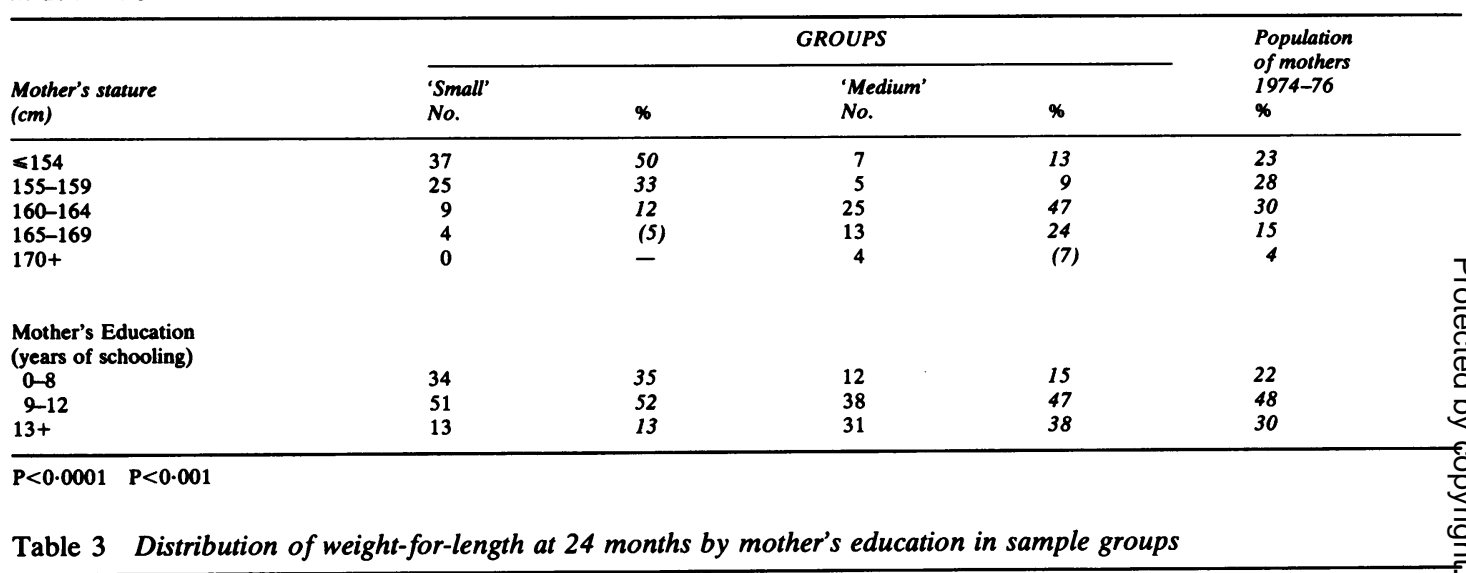

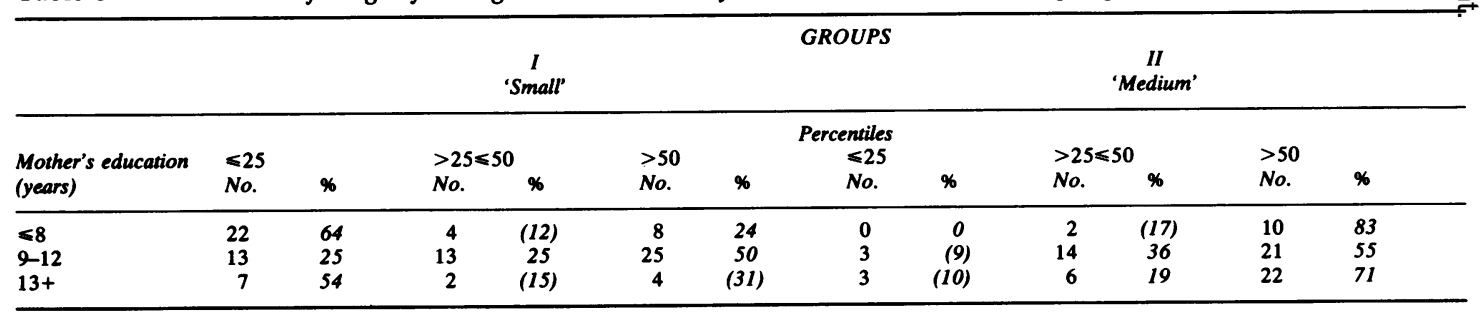

(P<0.0001) (Fig 4). There was a significant association between the father's occupation, the mother's stature, and her educational status in the cohorts. In the lower occupational categories $55 \%$ of mothers were below $155 \mathrm{~cm}$ tall and $15 \%$ were 165 $\mathrm{cm}$ or above; in the highest category the proportions were reversed: $15 \%$ and $32 \%$ respectively $(P<0 \cdot 05)$. In the lowest occupational category, 55\% of mothers had had eight years of schooling or less and none more than 12 years; in the professional category the proportions were $2 \%$ and $60 \%$ respectively (P<0.0001).

A larger percentage of fathers of 'small' infants were in the lowest occupational category. The 'medium' infants were distributed as expected from total cohort data (Table 4).
More mothers of 'small' than of 'medium' infants had come from North Africa and more mothers of 'medium' than 'small' infants from 'Asia' and the 'West' respectively. (Table 4 ). In the cohorts $25 \%$ of mothers were born in North Africa; of this group $35 \%$ had had less than nine years of schooling, while none in this group had had more than 12 years. The percentages with less than nine years of schooling for the other three regions of origin were: 'Asia' 23\%; Israel 18\%; and the 'West' 7\%, and with more than 12 years' schooling $10 \%, 37 \%$, and $38 \%$. These trends held true for the sample groups but did not reach levels of significance.

OTHER FACTORS

None of the 'medium' infants had mothers aged under 20 , but $14 \%$ of the 'small' infants did; only two 
Table 4 Distribution of father's occupation and mother's region of origin by sample groups and combined half cohort of 1973-74

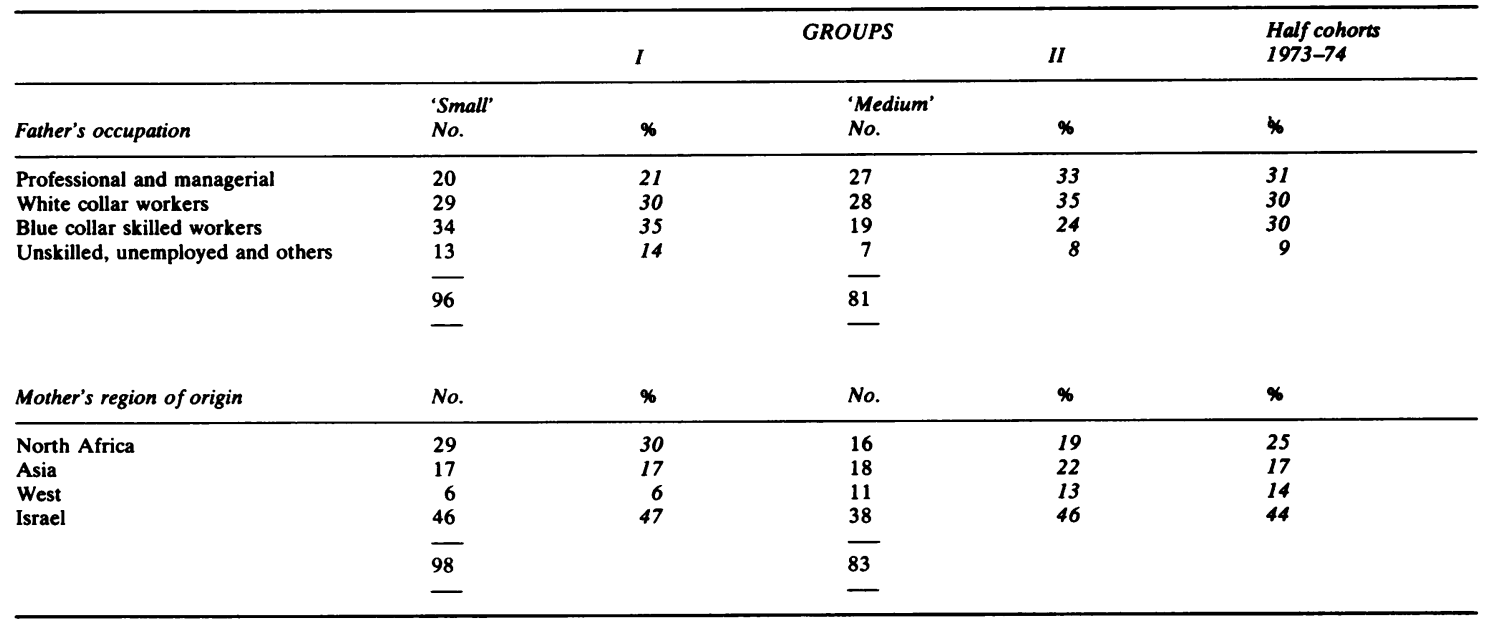

'medium' and three 'small' infants had mothers aged 40 or over. Few problems were registered under the '28th day' programme for the duration of pregnancy, at delivery, or the condition of the baby at birth in the sample groups. The differences were not significant. In both groups $70 \%$ of infants were first or second born.

The hospitalisation rate in the first year of life in both groups was $14 \%$. Only tour infants were hospitalised for conditions other than infections. Differences between the groups were insignificant.

\section{Discussion}

One does not have to be tall to be clever. Nevertheless there are more tall people in the higher socioeconomic classes and tall women have bigger babies and healthier, cleverer children. 1213

Although the birthweight distribution in a selected neighbourhood of western Jerusalem is in accordance with US standards, there is an excess of children on or below the 10th percentile for length at the age of 24 months in spite of regular attention during pregnancy and infancy. Eighty per cent of the 'small' infants showed a downward deviation of percentiles by 10 centiles or more away from the median between birthweight and the 12- or 24-month measurements. One may consider this abnormal growth. The major downward changes in percentile shift had already occurred by the age of 12 months. In both groups little change in weight percentiles occurred thereafter, while changes in length percentiles continued.

On the basis of this information, routinely obtained in the first year, a prediction could be made at the age of 12 months of the expected growth attainment of individual infants by the age of 24 months in all but nine $(5 \%)$ cases, and real 'misclassification' would have occurred in only three infants. Other evidence of the inadequate progress of 'small' infants was provided by the higher incidence in this group of 'underweight' infants, especially boys, compared with the 'medium' group. Eight 'small' boys could be classified by international standards as 'first degree malnutrition'. ${ }^{14}$

The US reference standard was selected as a basis for comparison on the strength of the small contribution made by ethnic factors alone in population studies, ${ }^{15}$ as well as the good correlation shown with Israeli infants at 30 and 48 months. $^{8}$
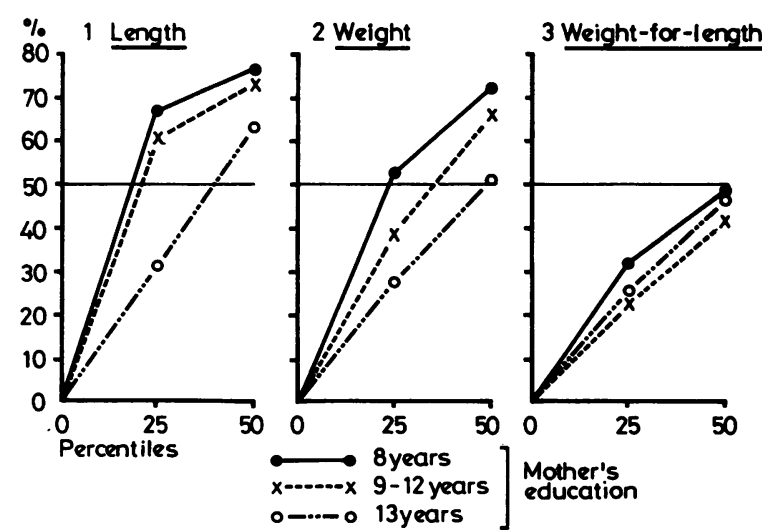

Fig. 4 Cumulative frequency diagrams up to 50th percentiles for length, weight, and weight-for-length at age 24 months by mother's education in 1973-74 cohorts. 
Birthweight must continue to be viewed as a major determinant of stature. ${ }^{16}$ Nevertheless, birthweight alone 'explained' only $20 \%$ of the 'small' infants. Another important factor is mother's stature. ${ }^{17}{ }^{18} \mathrm{In}$ the group of 'small' infants, $50 \%$ had a mother under $155 \mathrm{~cm}$ tall. This proved to be so closely related to variables of socioeconomic status, as expressed by mother's education and father's occupation, as to be indistinguishable from them. The most important of the two variables appeared to be mother's educational level. Of the mothers with eight years of schooling or less, $70 \%$ had infants in the 'small' group. Although few of the mothers with more than eight years of schooling were short, it seems wise to retain both stature and education as separate risk predictors because the influence of parental size has been shown to gain in importance in the well-educated. ${ }^{16-19}$

On the basis of studies in Israel on birthweight and growth in the early months, infants of mothers of North African origin ought to be among those in the higher percentiles later ${ }^{20-22}$; in this study, however, such infants were more frequently in the lower percentiles than those of other ethnic groups. The excess of short mothers was greatest among those originating from North Africa when the mothers' heights in the selected neighbourhood were compared with figures from the United States. ${ }^{23}$ Most of the North African mothers who were short had had eight years schooling or less and manual occupations predominated among their husbands. If it is accepted that the secular trend may facilitate the expression of the genetic input while a disadvantaged environment may suppress it, ${ }^{15}{ }^{19-28}$ it seems likely that the shortness of the mothers of North Africa and of their infants at 24 months was determined by adverse circumstances. As has been shown elsewhere, the effect of region of origin is overshadowed by the strength of the correlation with educational attainment. ${ }^{27}$

A number of important factors associated with pregnancy and delivery did not yield meaningful differences due to the low frequency of occurrence in the sample. There was a slightly higher percentage of mothers under 20 who had 'small' infants than in the 'medium' group. In general, the available figures suggest that expected trends remain.27-30 Hospitalisation in the first year occurred in the percentage expected for the area ${ }^{31}$ and was generally of short duration, which is unlikely to affect growth. ${ }^{32}$

\section{Conclusions}

The relationship between growth and infant mortality and morbidity, especially when growth disturbance is severe, is a well-worn theme..$^{2633-35}$
Maternal education proves to be an important risk indicator for these problems. ${ }^{27}{ }^{36}{ }^{37} \mathrm{It}$ is interesting that a link is shown between education of the mother and growth of the infant in a population where infant mortality is no longer a major problem and where adequate facilities exist for the prevention and treatment of most infant diseases. The remaining concern in such societies with respect to the disadvantaged child is to ensure adequate mental and social development. ${ }^{38}{ }^{39}$ The link with socioeconomic disadvantage and family disintegration is generally accepted, ${ }^{10-42}$ but the measures continue to be elusive. The connection between maternal education and infant mental development has been carefully explored in Israel. ${ }^{43} 44$

Previous studies in the area have shown that the observed poor growth is not due to the quality or quantity of food offered. ${ }^{45}$ In malnourished populations it has proved almost impossible to separate the effects of nutrition from those of social environment. ${ }^{3433}$ When inadequate intrauterine or postnatal growth is coupled with adverse social and environmental circumstances the effects on development appear to be confounded. ${ }^{6}{ }^{46}$

The study shows that the determinants of $\frac{+}{\mathrm{D}}$ inadequate growth in a generally well-provided society overlap with those of inadequate mental and social development. One should therefore consider 8 such deviant growth an indicator of multiple risks. These children may be identified by the age of $12 \mathrm{c}$ months and possibly even earlier. ${ }^{47}$ Although infants of mothers with eight years schooling or less appear vulnerable, some do well. It would seem that the functioning of care-bonding relationships remains the key to normal development. ${ }^{412}$ 48-50 It would help if one could narrow down the target group for intervention to those with disturbances of these functions. Identification of this is not as simple as the identification of deviant growth, but it should be attempted.

Reprints from Dr. Hava Palti, Hebrew UniversityHadassah Medical School, PO Box 1172, Jerusalem, Israel.

\section{References}

${ }^{1}$ Birch HG, Gussow JD. Disadvantage Children. New York: Harcourt-Brace, 1970.

${ }^{2}$ Hepner R, Maiden NC. Growth rate, nutrient intake, and 'mothering' as determinants of malnutrition in disadvantaged children. Nutr Rev 1971; 29: 219-23.

${ }^{3}$ Hertzig ME, Birch HG, Richardson SA, Tizard J. Intellectual levels of schoolchildren severely malnourished in the first two years of life. Pediatrics 1972; 49: 814-29. 
'Levitsky DA, ed. Malnutrition, Environment and Behaviour. New York and London: Cornell University Press, 1979.

${ }^{5}$ Kark SL. Epidemiology and Community Medicine. New York: Appleton-Century-Corfots, 1974.

${ }^{6}$ Werner E, Bierman, JM, French FE. The Children of Kauai. A Longitudinal Study from the Prenatal Period to age 10. Honolulu: University of Hawaii Press, 1971.

${ }^{7}$ Palti H, Adler B, Shamir Z, Kark SL. Community diagnosis of physical growth of infants based on monitoring in a routine preventive service. $J$ Epidemiol Community Health 1979; 33: 292-6.

${ }^{8}$ Palti H, Reshef A, Adler B. Food intake and growth of children between 30 and 48 months of age in Jerusalem. Pediatrics 1979; 63: 713-8.

${ }^{9}$ National Center for Health Statistics. Growth curves for children from birth-18 years. Series 11 No. 165. Washington DC: US Department of Health, Education and Welfare, 1977.

${ }^{10} \mathrm{Nie} \mathrm{NH}$, Bent DH, Hull CH. Statistical Package for the Social Sciences. New York: McGraw Hill, 1970.

${ }^{11}$ Fitzharding PM, Steven EM. The small-for-date infant. I: Later growth patterns. Pediatrics 1972; 49: 671

11a Fitzharding PM, Stevens EM. The small-for-date infant. II: Neurological and intellectual sequelae. Pediatrics 1972; 50: 50-7.

${ }^{12}$ Klein RE, Freeman HE, Kagan J, Yarbrough C, Habicht JP. Is big smart? The relation of growth to cognition. $J$ Health Soc Behav 1972; 13: 219.

${ }^{13}$ Thomson AM. Historical perspectives of nutrition, reproduction, and growth. In: Scrimshaw NS, Gordon JE, ed. Malnutrition, Learning and Behaviour. Cambridge, Mass: MIT Press, 1968: 17-29.

${ }^{14}$ Waterlow JC. Classification and definition of PCM. In: Beaton GH, Bengoa, JM, ed. Nutrition in Preventive Medicine. Annex 5. Geneva: World Health Organisation, 1976: 530-56.

${ }^{15}$ Habicht JP, Martorell R, Yarbrough C, Malina RM, Klein RE. Weight and weight standards for preschool children. How relevant are ethnic differences in growth potential? Lancet 1974; i: 611-5.

${ }^{16}$ Garn SM, Shaw HA, McCabe KD. Birth size and growth appraisal. J Pediatr 1977; 90: 1049-51.

${ }^{17}$ Wingerd J, Schoen EJ. Factors influencing length at birth and height at 5 years. Pediatrics $1974 ; 53: 737-41$.

${ }^{18}$ Tanner JM. Charts for the diagnosis of short stature and low growth velocity, allowance for height of parents and prediction of adult height. In: Bergsma D, Schimke RN, ed. Growth Problems and Clinical Advances. The National Foundation 1976: 1-13.

${ }^{19}$ Garn SM. Body size and its implications. In: Hoffman LW, Hoffman MZ, ed. Review of Child Development Research, Voi. 2. New York: Russell Sage Foundation, 1966: 529-61.

${ }^{20}$ Epstein JM. Growth in weight of infants in the western region of Jerusalem, Israel. J Trop Pediatr 1968; 14: $139-48$.

${ }^{21}$ Legg S, Davies AM, Prywes R, Sterk VV, Weiskopf P. Patterns of low birth weight in western Jerusalem with special reference to maternal origin. Br J Prev Soc Med 1970; 24: 89-96.

${ }^{22}$ Palti H, Adler B. Body size of Israeli newborn infants in relation to regional origin of their mothers. Hum Biol 1977; 49: 41-50.

${ }^{23}$ Owen GM, Kram KM, Garry PJ, Lowe JE, Lubin HA. Study of nutritional status of preschool children in the United States 1968-1970. Pediatrics 1974 ; 53, suppl 4: 597-641.

${ }^{24}$ Bakwin $\mathrm{H}$, McLaughlin SM. Secular increments in height-is the end in sight? Lancet 1964; ii: 1195-6.

${ }^{25} \mathrm{Garn}$ SM, Clark DC. Nutrition, growth, development and maturation-findings from the ten-State nutrition survey of 1968-70. Pediatrics 1974; 56: 306-19.

${ }^{28}$ Habicht JP, Lechtig A, Yarbrough C, Klein RE. In: Size and Birth. CIBA Symposium 27 (new series). Amsterdam: Elsevier-Excerpta Medica, 1974: 353-70.

${ }^{27}$ Chase HC. A study of risks, medical care and infant mortality. Am J Public Health 1973; 63: 1-41.

${ }^{28}$ Butler NR, Alberman ED. Perinatal Problems. Second Report of the 1958 British Perinatal Mortality Survey. Edinburgh and London: Churchill Livingstone, 1969.

${ }^{29}$ Gold EM, Stone ML, Rich H. Total Maternal and infant care: an evaluation. Am J Public Health 1969; 59: 1851-6.

${ }^{30}$ Goldstein KM, Caputo DV, Taub HB. The effects of prenatal and perinatal complications on development at 1 year of age. Child Dev 1976; 47: 613-21.

${ }^{31}$ Harlap S, Stenhouse NN, Davies AM. Multiple regression analysis of admission of infants to hospital: report from Jerusalem perinatal study. Br J Prev Soc Med 1973; 27: 182-7.

${ }^{32}$ Quinton D, Rutter M. Early hospital admission and later disturbances of behaviour-an attempted replication of Douglas's findings. Dev Med Child Neurol 1976; 18: 447-60.

${ }^{33}$ Scrimshaw NS, Taylor CE, Gordon JE. Interaction of Nutrition and Infection. WHO Monograph Series No. 57. Geneva: World Health Organisation, 1968.

${ }^{34}$ Scrimshaw NS, Gordon JE, ed. Malnutrition, Learning and Behaviour. Proceedings of the International Conference of the Nutrition Foundation and the Massachusetts Institute of Technology, Cambridge, Mass, March 1-3 1967. Cambridge, Mass: MIT Press, 1968.

${ }^{35}$ Kielman AA, McCord C. Weight for age as an index of death in children. Lancet 1978; 1: 1247-50.

${ }^{36}$ Christianson N, Mora JO, Herrera MG. Family social characteristics related to physical growth of young children (Bogotá). Br J Prev Soc Med 1975; 29: 121-30.

${ }^{37}$ Winter ST, Lilos, P. Prediction of hospitalization during infancy: scoring the risk of admission. Pediatrics 1974; 53: 716-20.

${ }^{38}$ Mitchell RG, ed. Changing concepts of risk. Dev Med Child Neurol 1975; 17: 277-8.

${ }^{39}$ Vahlquist B. Child health across boundaries. Pediatrics 1977 59: 154-164.

${ }^{40}$ Caldwell BM, Ricciuti HN, ed. Child Development and Social Policy. Review of Child Development Research Vol 3. Chicago and London: University of Chicago Press, 1973.

${ }^{4}$ Rutter M. Maternal Deprivation Reassessed. London: Penguin Books, 1979.

${ }^{42}$ Clarke AM, Clarke ADB. Early Experience-The Myth and the Evidence, London: Open Books, 1976. 
${ }^{43}$ Smilansky S, Shephatia L, Frenkel E. Mental Development of Infants from two Ethnic Groups-Findings from the Jerusalem Study of Growth and Development. Research Report No. 195. Jerusalem: Henrietta Szold Institute, 1976.

"Palti H, Gitlin M, Zloto R. Psychomotor development of children at 2 years in Jerusalem. Journal of Cross-Cultural Psychology 1977; 8: 453-64.

${ }^{45}$ Palti H, Adler B, Reshef A. A semilongitudinal study of food intake, anaemia rate and body measurements of 6-24 months old children in a Jerusalem community. Am J Clin Nutr 1977; 30: 268-74.

${ }^{46}$ Ricciutti HN. In: Levitsky DA, ed. Malnutrition, Environment and Behaviour. New York and London: Cornell University Press, 1979.
${ }^{47}$ Palti H, Adler B, Shamir Z, Peritz E. Identification of infants 'at risk' through the study of growth patterns in a community. Paper read at the conference 'Child-at-risk', Tel Aviv, July 1979.

48 Bowlby J. Maternal Care and Mental Health. WHO Monograph No. 2. Geneva: World Health Organisation, 1951.

${ }^{49}$ Latham MC, Cobos F. The effects of malnutrition on intellectual development and learning. Am J Public Health 1971; 61: 1307-24.

${ }^{\text {so }}$ Tulkin SR, Kagan J. Mother-child interaction in the first year of life. Child Dev 1972; 43: 31-41. 